Article

\title{
Evaluation of Comfort Level and Harvested Energy in the Vehicle Using Controlled Damping
}

\author{
Vytautas Bucinskas ${ }^{1}$, Peter Mitrouchev ${ }^{2}$, Ernestas Sutinys ${ }^{1}$, Nikolaj Sesok ${ }^{1}$, Igor Iljin ${ }^{1}$ \\ and Inga Morkvenaite-Vilkonciene ${ }^{1, *}$ \\ 1 Department of Mechatronics and Robotics, Vilnius Gediminas Technical University, J. Basanavičiaus g. 28, \\ 03224 Vilnius, Lithuania; vytautas.bucinskas@vgtu.lt (V.B.); ernestas.sutinys@vgtu.lt (E.S.); \\ nikolaj.sesok@vgtu.lt (N.S.); igor.iljin@vgtu.lt (I.I.) \\ 2 G-SCOP, Grenoble INP, University Grenoble Alpes, F-38000 Grenoble, France; \\ Peter.Mitrouchev@grenoble-inp.fr \\ * Correspondence: inga.morkvenaite-vilkonciene@vgtu.lt; Tel.: +370-5-2744752
}

Received: 29 September 2017; Accepted: 25 October 2017; Published: 30 October 2017

\begin{abstract}
Shock absorbers allow the damping of suspension vibrations, by dissipating kinetic energy. This energy theoretically can be harvested; however, practical solutions are not easily obtainable. This paper is dedicated to analyzing and evaluating the vibration energy in a vehicle's suspension that is generated by road excitations. Also, it estimates the possible amount of harvested energy required to diminish accelerations of the vehicle body, the driver, or the passenger center of mass. The control of damper is realized by optimizing the best damping coefficient for different road roughness. Analytical results, obtained from the proposed dynamic model of the car, were compared with experimental data, showing a good coherence between them. These results allow us to evaluate the amount of energy circulating within shock absorbers and give information about the amount of the possible harvested energy. There is a very good relationship between energy needed for control and gained energy.
\end{abstract}

Keywords: shock absorber; controllable damper; energy harvester

\section{Introduction}

Energy harvesting and vibration control from large amplitude and low frequency vibrations is a promising research area [1-11]. Electromagnetic (EM) transducers are widely used for this purpose. Transducers can be coupled to a permanent-magnet synchronous machine [1], or linear motion EM devices [2,10], which can be used for both vibration damping and energy harvesting. An energy harvesting-enabled tuned mass-damper-inerter system comprises a mass, grounded via an electromagnetic motor (energy harvester)-inerter layout [8]. An electromagnetic resonant shunt tuned mass-damper-inerter was proposed by Luo et al. [9]. This control device can help in minimizing structure damage and simultaneously harvest energy under random wind excitation [9]. Vibration control, together with energy harvesting, possibly could be realized, by using a vibration absorber, supplemented with a piezoelectric stack [4,7]. However, such vibration control systems can be applied only to high vibration frequencies, since the output power at low frequencies becomes very small. Moreover, the piezoelectric energy harvester maximum generated power is in the range of milliwatts $[12,13]$.

A vehicle's damping system control should comply with specific purposes, such as passenger riding comfort and the vehicle's handling quality improvement [14-17]. A recent study demonstrated a significant enhancement in harvested power and the frequency bandwidth of a multimodal electromagnetic vibration energy harvester, consisting of arrays of coupled levitated magnets [18], when the device is excited beyond its critical Duffing amplitude [19]. The automobile shock 
absorber practically always works under random excitations [7], caused by the irregularity of road surface, and during acceleration or braking [20-25]. The intensity of these excitations is proportional to the vehicle speed. Different control techniques could be used for vibration control in a car. One amongst the most effective and low-cost systems is semi-active $[3,26]$ with magnetorheological (MR) dampers $[14,16,27]$. Such systems are used to minimize the response to external disturbances, with a small amount of power, compared to active systems [28]. MR dampers are widely used in the automotive industry, train suspension systems, seismic protection and in cable-stayed bridges [29-31]. Semi-active vibration control systems could be composed of an MR damper and an electromagnetic vibration energy harvester. Harvested energy in such systems is used to power the MR damper. Another way to suppress the vibration and harvest the energy is to use acoustic-elastic material metastructure with piezo elements [32,33]. However, finding optimal parameters for such system control is complicated, because for vibration suppression and for energy harvesting performances, the parameters have to be tuned in opposite directions. Therefore, for such damping/harvesting systems, the quality of damping/harvesting is a compromise: when damping is improved, harvested energy is small, and vice versa.

The control of semi-active systems with MR dampers are often realized by controlling the viscosity of the magnetorheological fluid. However, using this control method, heat is generated in the inductor coil as well as energy dissipation from vibrations. The main problem of dampers of this type, is the excess heat, which decreases its working effectiveness. On the other hand, the damper works with only some limitations in time and coil current. Moreover, the fluid must be cooled and pumped over. Thus, such type of damper could not be used as an energy harvester.

In order to extract as much energy as possible from the energy harvester, it is necessarily to adopt proper AC/DC converter topologies and control techniques, such as those reported in [34-37]. In practice, joint mechanical and electrical optimization is necessary.

The new type of damper-energy harvester device, based on implementation of ferro-nanomagnetic fluid was presented in [14]; this particular fluid is used as: (i). ferromagnetic media; (ii). lubricant for bonding surfaces; and (iii). hydraulic fluid for vibration damping, as in classic shock absorbers in vehicles. To take full advantage of this device, a specific mathematical model is necessary to evaluate the generation of power from vibration and consequently to create the control system. Different mathematical models for similar devices have been proposed-from an individual MR damper model to models of the whole car body. Many authors are trying to optimize dampers using different control algorithms, models and controllers, such as: (i). semi-active damping force estimator [38]; (ii). sliding model controller [21]; (iii). skyhook, ground hook and hybrid systems [39]; (iv). 8 degrees of freedom (DOF)whole body vehicle model [23]; (v). non-parametric linearized data driven model [28]; (vi). skyhook controller in hardware-in-the-loop simulation [22]; (vii). hybrid control [40]; (viii). valve system optimization model [41]; (ix). vibration control method, used in earthquakes [11]; (x). variable damping coefficients observation by controlling the electrical load of the shock absorber [42]. The latter findings most relate to our research-we are trying to find optimized damping coefficient values, which will be realized using the real vibration control and harvesting system, proposed in [14]. In [42] authors presented variable damping coefficients. However, in this case, controllable electrical current was applied for damping control, thus, the damping coefficient was not changed according to vibration characteristics. Thus, it is not possible to change the moving regime without feedback. Moreover, there is no possibility of harvesting the energy and using it for damper control. In commercially available systems, three main places of the vehicle are usually damped: the tire, suspension, and seat. The mathematical models, mentioned above, do not evaluate all these parameters either. Additionally, our model evaluates another important shock absorber application possibilities-harvesting energy from vibrations. There are some problems in using shock absorbers as automobile energy harvesters: (i). vibrational energy systems may not achieve the entire frequency range needed for harvesting and (ii). optimizing energy harvesting and vibration damping are often competing goals [14]. 
In this context, the main aim of this research is to propose a new damping system control method, with optimized damping coefficients, of which values are related to road roughness and to evaluate this optimized control effect for the amount of generated energy. The paper presents a new damping system control method and the possibility to apply such a system for energy harvesting. Our control method, presented here, and device, proposed in [14], could be applied to the harvest of all types of vibration energy, including vibrations from earthquakes. However, at low frequency vibrations, which usually occur in buildings, the amount of harvested energy will be very low.

\section{Materials and Methods}

Experiments were performed by the car, Range Rover Evoque, on two roads-road no. 6 (coarsest) and road no. 3 (medium roughness) - with the driver, whose mass was $80 \mathrm{~kg}$, but without passengers or baggage. Acceleration were measured by two accelerometers (damping coefficient $7500 \mathrm{Ns} / \mathrm{m}$ ), placed in the car, Range Rover Evoque, as shown in Figure 1. The speed of the car was $60 \mathrm{kph}$. Measurements were performed using industrial equipment, piezoelectric accelerometers (603C01 from PCB Piezotronics, Depew, NY, USA), and a data acquisition device (NI 4431 from National Instruments, Austin, TX, USA). Data were collected using the National Instruments Software Package, LabView 2015. In order to compare experimental and analytical data, the damping force was calculated from an experimentally-observed suspension position:

$$
F_{\exp }=h_{s F 1} \cdot \dot{Z}+k_{s F} \cdot Z
$$

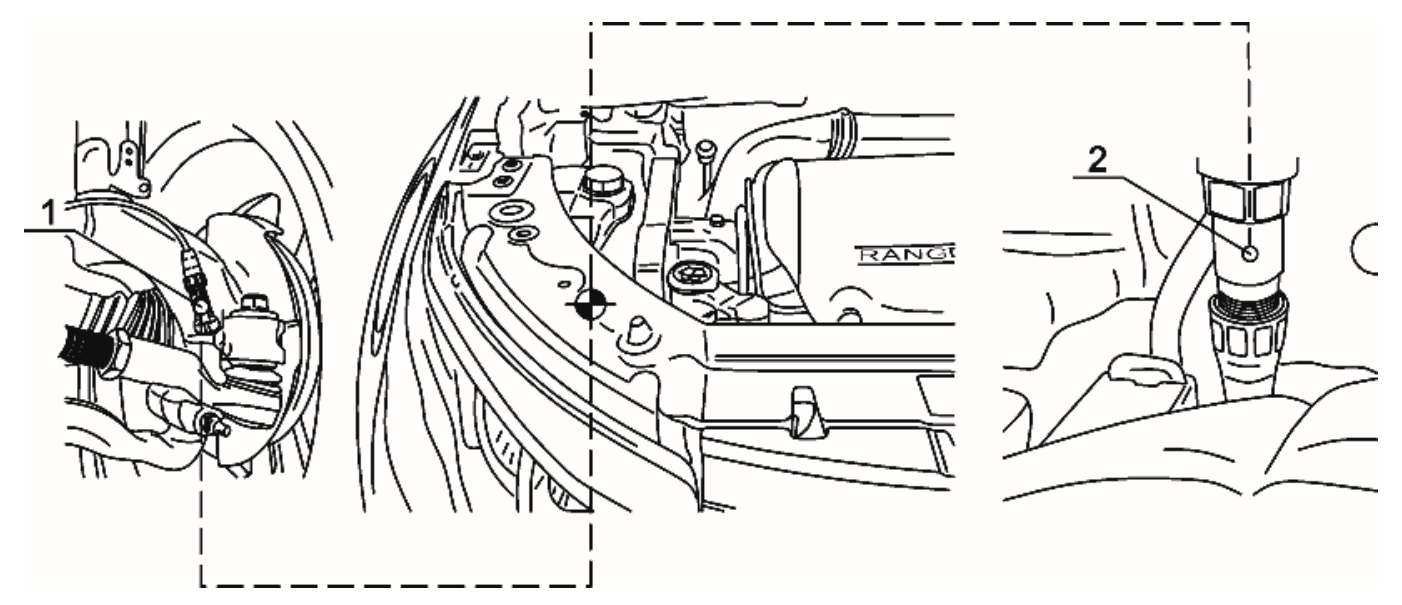

Figure 1. Experimental equipment; 1 and 2 represent accelerometers.

The model was solved using MatLab version 2014b. The simulation took $1 \mathrm{~min}$ for each $1 \mathrm{~s}$ of real road. Equations were solved in Simulink, by means of the standard fourth order Runge-Kutta solver.

\section{Mathematical Model}

\subsection{Dynamic Model of the Vehicle}

The model of the car body included ten masses and two moments of inertia. Other masses and moments of the car are reduced by joining them with respect to the transfer ratio of the suspension levers. The model also included four passengers' masses and the mass in the baggage box, as presented in Figure 2. The masses of the tires and the rims were included into suspension masses; they have independent coordinates.

In the proposed model, the car frame is regarded as a rigid body and is here named the system, as the stiffness of it is a few orders of magnitudes higher than the suspension stiffness. The movement 
of the system is described with the coordinate of the vertical axis, $Z$, and the rotation angles, $\varphi_{x}$ and $\varphi_{y}$, about the axes, $X$ and $Y$, respectively. The origin is considered to coincide with the stiffness center in the plane of the suspension springs of the upper point. In general, the center of gravity does not coincide with the center of stiffness. Coordinates of the center of gravity with respect to the center of stiffness are denoted as $x_{s}, y_{s}$ and $z_{s}$.

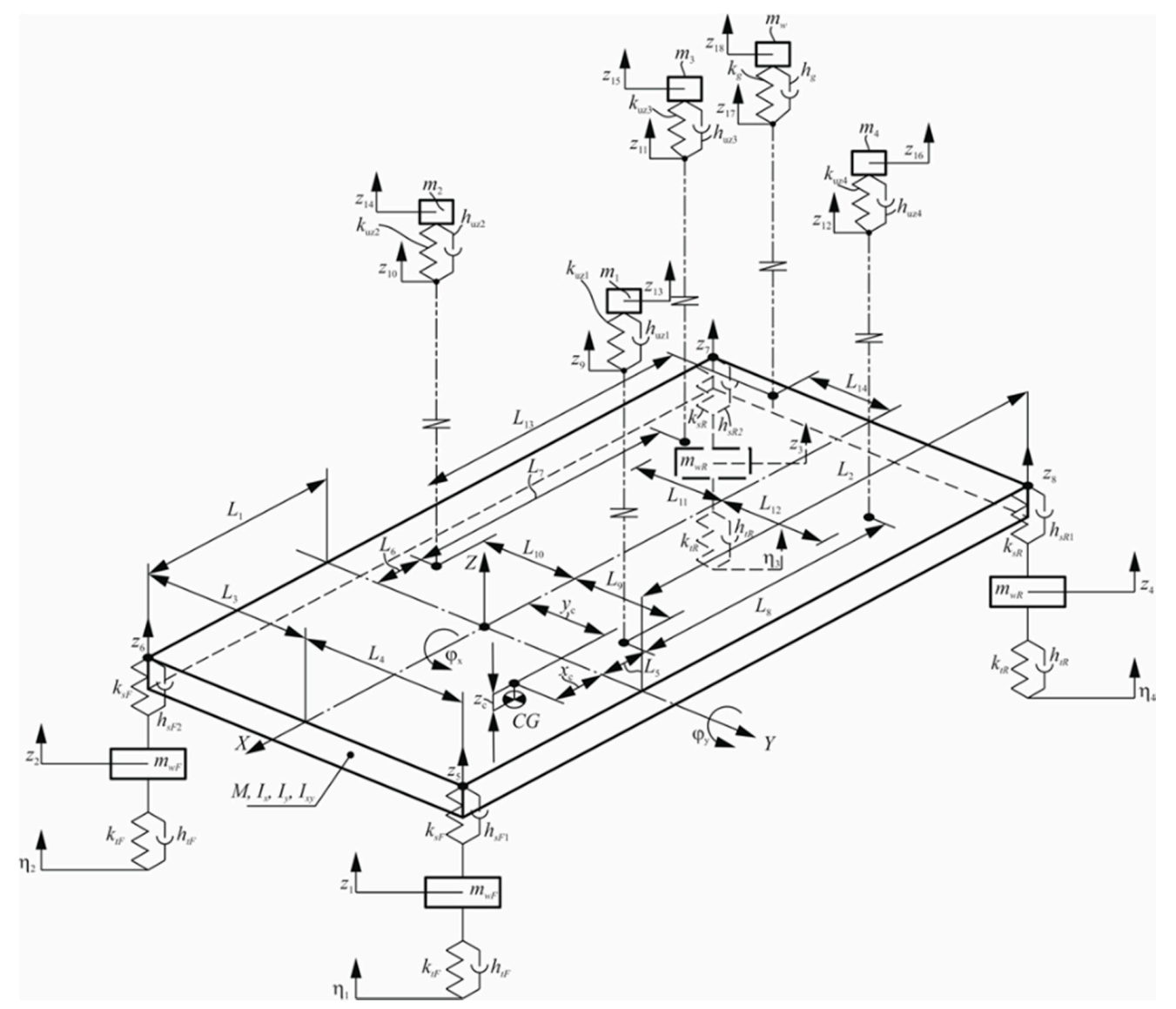

Figure 2. Dynamic model of the car body. CG—center of gravity; $Z$ —coordinate of the vertical axis; $X$ and $Y$-coordinates of horizontal axes; $\varphi_{x}$ and $\varphi_{y}$ are the rotation angles about the axes $X$ and $Y$, respectively; $x_{s}, y_{s}$ and $z_{s}$-coordinates of CG with respect to the center of stiffness; $z_{1}, z_{2}, z_{3}, z_{4}$ - the coordinates of vertical movements of wheels; $z_{5}, z_{6}, z_{7}, z_{8}$-auxiliary coordinates at the shock absorbers' points, $z_{9}$, $z_{10}, z_{11}, z_{12}$ - the points of seat contact with the passengers' bodies and $z_{17}$-the point of the luggage compartment; $z_{13} \ldots z_{16}$-coordinates of the center of masses of the driver and three passengers, respectively, $z_{18}$ - coordinate of center of mass of baggage in the baggage box; $\mathrm{M}$-mass of the car; $J_{x}$ and $J_{y}$ 一the moments of inertia about the respective axis; $J_{x y}$ 一the mixed moment; $k_{s F}$-stiffness coefficients of the front wheel suspension of individual elastic elements; $k_{s R}$-stiffness coefficients of the rear wheel suspension of individual elastic elements; $h_{s F 1}, h_{s F 2}, h_{S R 1}, h_{S R 2}$ - the damping coefficients; $m_{w F}$ and $m_{w R}$ - the suspension mass and the rear mass; $k_{S F}$ and $k_{s R}$ - the front and the rear wheel tires spring elements coefficients of stiffness, respectively; $h_{S F}$ and $h_{s R}$ - the coefficients of damping for the front and the rear wheel, respectively; $m_{1}, m_{2}, m_{3}, m_{4}, m_{w}$-masses, $k_{u z 1}, k_{u z 2}, k_{u z 3}, k_{u z 4}, k_{g}$-coefficients of stiffness, and $h_{u z 1}, h_{u z 2}, h_{u z 3}, h_{u z 4}, h_{g}$-damping coefficients of the driver, three passengers and load in the baggage box, respectively; $L_{1}, \ldots, L_{14}$-distances; $\eta_{1}, \eta_{2}, \eta_{3}, \eta_{4}$-coordinates, at which the dynamic system (the car) was excited kinematically.

In the model, the parameters of the car body were: the mass of the car (M), the moments of inertia about the respective axis $\left(J_{x}\right.$ and $\left.J_{y}\right)$, and the mixed moment $\left(J_{x y}\right)$. Displacements in $X$ and $Y$ axes and rotations about the $Z$ axis were ignored, because only the main affecting vibrations in the vertical 
direction to the human body were evaluated. The suspension was modelled with elastic damping elements. It was considered that the elastic stiffness of the elements was linear.

Stiffness coefficients of the front wheel suspension of individual elastic elements are denoted as $k_{S F}$. Stiffness coefficients of the rear wheel suspension of individual elastic elements are denoted as $k_{s R}$.

Suspension shock absorbers here were modelled as nonlinear damping elements. The damping coefficients, $h_{S F 1}, h_{S F 2}, h_{s R 1}, h_{s R 2}$, depended on the velocity of vertical wheel movement caused by the roughness of the road. Here, the presented model evaluates only vertical movements of wheels, represented by the coordinates, $z_{1}, z_{2}, z_{3}, z_{4}$. In the model, the weight of the hub was evaluated as the sum of the masses of the tire, rim, axle, bearing and support. Suspension parts, which were connected to the lower suspension spring points were added to the reduced wheel masses, as unsuspended masses $\left(m_{w F}\right)$. It was assumed that the suspension mass $\left(m_{w F}\right)$ and the rear mass $\left(m_{w R}\right)$ were included in the front wheel mass. It was also assumed that the tire of the vehicle is modelled as a spring with a damper. The front wheel tire spring element coefficient of stiffness was marked as $k_{S F}$, for the rear wheel $\left(k_{s R}\right)$. The coefficients of damping are marked $h_{s F}$ and $h_{s R}$, respectively.

The driver, three passengers and load in the baggage box were modelled as masses, $m_{1}, m_{2}, m_{3}$, $m_{4}, m_{w}$, mounted on the stiffness elements, $k_{u z 1}, k_{u z 2}, k_{u z 3}, k_{u z 4}$ and $k_{g}$, with dampers, $h_{u z 1}, h_{u z 2}, h_{u z 3}$, $h_{u z 4}$ and $h_{g}$, respectively.

Stiffness elements were applied to the vehicle body by distances, $L_{1}, \ldots, L_{14}$. The dynamic system (the car) was excited kinematically along the coordinates, $\eta_{1}, \eta_{2}, \eta_{3}, \eta_{4}$. In this case, the principle of relativity to the car body admits that the car is staying immobile in the horizontal plan and the road is moving.

The status of the dynamic behavior of the vehicle was defined by twelve generalized coordinates- $Z, \varphi_{x}, \varphi_{y}, z_{1}, z_{2}, z_{3}, z_{4}, z_{13}, z_{14}, z_{15}, z_{16}, z_{18}$. For the purpose of better visualization and to build general equations, there were also some defined auxiliary coordinates: the shock absorbers' points $\left(z_{5}, z_{6}, z_{7}, z_{8}\right)$, the points of seat contact with the passengers' bodies $\left(z_{9}, z_{10}, z_{11}, z_{12}\right)$ and the point of the luggage compartment $\left(z_{17}\right)$.

All coefficients of stiffness $\left(k_{s F}, k_{s R}\right)$, distances $\left(L_{1}, \ldots, L_{4}\right)$, coordinates of center of gravity $\left(x_{s}, y_{s}\right.$, $\left.z_{s}\right)$, masses $\left(M_{i}, m_{w F}, m_{w R}\right)$ and moments of inertia $\left(J_{x}, J_{y}, J_{x y}\right)$ were available from real Range Rover Evoque car data (Table 1).

Interactions of the driver (passenger) with the seat were represented by coefficients of stiffness $\left(u_{z 1}, k_{u z 2}, k_{u z 3}, k_{u z 4}\right)$ and coefficients of damping $\left(h_{u z 1}, h_{u z 2}, h_{u z 3}, h_{u z 4}\right)$.

The model also included the mass of the load $\left(m_{w}\right)$, the coefficient of stiffness between the load and the car body $\left(k_{g}\right)$ and the coefficient of damping $\left(h_{g}\right)$. The behavior of the system was studied by Lagrange's equation of the second kind:

$$
\frac{d}{d t}\left(\frac{\partial T}{\partial \dot{q}_{i}}\right)-\frac{\partial T}{\partial q_{i}}+\frac{\partial \phi}{\partial \dot{q}_{i}}+\frac{\partial \Pi}{\partial q_{i}}=F_{i}(t)
$$

where $T$ and $\Pi$ are the kinetic and potential energies of the system, respectively; $\Phi$ is the function of dissipation; $q_{i}$ and $\dot{q}_{i}$ are thegeneralized coordinate and its derivative, with respect to time $(t) ; F_{i}(t)$ is the external generalized force, acting along the generalized coordinate, $q_{i}$.

As the system was excited only kinematically, external forces were neglected and Equation (2) became a homogenous one.

In the dynamic model, the center of stiffness and the gravity center do not coincide; therefore, the functions of energies were:

Kinetic energy:

$$
\begin{aligned}
& T=\frac{1}{2}\left(M \dot{z}^{2}+J_{x} \dot{\varphi}_{x}^{2}+J_{y} \dot{\varphi}_{y}^{2}-2 J_{x y} \dot{\varphi}_{x} \dot{\varphi}_{y}+2 M \dot{z}\left(x_{c} \dot{\varphi}_{y}-y_{c} \dot{\varphi}_{x}\right)+m_{w F} \dot{z}_{1}^{2}+m_{w F} \dot{z}_{2}^{2}+\right. \\
& \left.+m_{w R} \dot{z}_{3}^{2}+m_{w R} \dot{z}_{4}^{2}+m_{1} \dot{z}_{13}^{2}+m_{2} \dot{z}_{14}^{2}+m_{3} \dot{z}_{15}^{2}+m_{4} \dot{z}_{16}^{2}+m_{w} \dot{z}_{18}^{2}\right) .
\end{aligned}
$$


Potential energy:

$$
\begin{aligned}
& \Pi=\frac{1}{2}\left(k_{s F} \Delta_{1}^{2}+k_{s F} \Delta_{2}^{2}+k_{s R} \Delta_{3}^{2}+k_{s R} \Delta_{4}^{2}+k_{t F}\left(z_{1}-\eta_{1}\right)^{2}+k_{t F}\left(z_{2}-\eta_{2}\right)^{2}+k_{t R}\left(z_{3}-\eta_{3}\right)^{2}+\right. \\
& \left.+k_{s R}\left(z_{4}-\eta_{4}\right)^{2}+k_{u z 1} \Delta_{u z 1}^{2}+k_{u z 2} \Delta_{u z 2}^{2}+k_{u z 3} \Delta_{u z 3}^{2}+k_{u z 4} \Delta_{u z 4}^{2}+k_{g} \Delta_{w}^{2}\right)
\end{aligned}
$$

where:

$$
\begin{gathered}
\Delta_{1}=z_{5}-z_{1}=Z-L_{1} \varphi_{y}+L_{4} \varphi_{x}-z_{1}, \\
\Delta_{2}=z_{6}-z_{2}=Z-L_{1} \varphi_{y}-L_{3} \varphi_{x}-z_{2}, \\
\Delta_{3}=z_{7}-z_{3}=Z+L_{2} \varphi_{y}-L_{3} \varphi_{x}-z_{3}, \\
\Delta_{4}=z_{8}-z_{4}=Z+L_{2} \varphi_{y}+L_{4} \varphi_{x}-z_{4}, \\
\Delta_{u z 1}=z_{13}-z_{9}=z_{13}-Z-L_{9} \varphi_{x}-L_{5} \varphi_{y}, \\
\Delta_{u z 2}=z_{14}-z_{10}=z_{14}-Z+L_{10} \varphi_{x}-L_{6} \varphi_{y}, \\
\Delta_{u z 3}=z_{15}-z_{11}=z_{15}-Z+L_{11} \varphi_{x}-L_{7} \varphi_{y}, \\
\Delta_{u z 4}=z_{16}-z_{12}=z_{16}-Z-L_{12} \varphi_{x}-L_{8} \varphi_{y}, \\
\Delta_{w}=z_{18}-z_{17}=z_{18}-Z+L_{14} \varphi_{x}-L_{13} \varphi_{y}
\end{gathered}
$$

where $\Delta \mathrm{ij}$ is the linear elastic relative displacement (elongation) of the spring. The function of dissipation is:

$$
\begin{aligned}
& \Phi=\frac{1}{2}\left(h_{s F_{1}}\left(\Delta_{1}, \dot{\Delta}_{1}, \ddot{\Delta}_{1}\right) \dot{\Delta}_{1}^{2}+h_{s F_{2}}\left(\Delta_{2}, \dot{\Delta}_{2}, \ddot{\Delta}_{2}\right) \dot{\Delta}_{2}^{2}+h_{s R_{2}}\left(\Delta_{3}, \dot{\Delta}_{3}, \ddot{\Delta}_{3}\right) \dot{\Delta}_{3}^{2}+h_{s R_{1}}\left(\Delta_{4}, \dot{\Delta}_{4}, \ddot{\Delta}_{4}\right) \dot{\Delta}_{4}^{2}+\right. \\
& +h_{t F}\left(\dot{z}_{1}-\dot{\eta}_{1}\right)^{2}+h_{t F}\left(\dot{z}_{2}-\dot{\eta}_{2}\right)^{2}+h_{t R}\left(\dot{z}_{3}-\dot{\eta}_{3}\right)^{2}+h_{t R}\left(\dot{z}_{4}-\dot{\eta}_{4}\right)^{2}+h_{u z 1} \dot{\Delta}_{u z 1}^{2}+h_{u z 2} \dot{\Delta}_{u z 2}^{2}+ \\
& \left.+h_{u z 2} \dot{\Delta}_{u z 3}^{2}+h_{u z 4} \dot{\Delta}_{u z 4}^{2}+h_{g} \dot{\Delta}_{w}^{2}\right) ;
\end{aligned}
$$

where:

$$
\begin{aligned}
& \dot{\Delta}_{1}=\dot{z}_{5}-\dot{z}_{1}=\dot{Z}-L_{1} \dot{\varphi}_{y}+L_{4} \dot{\varphi}_{x}-\dot{z}_{1}, \\
& \dot{\Delta}_{2}=\dot{z}_{6}-\dot{z}_{2}=\dot{Z}-L_{1} \dot{\varphi}_{y}-L_{3} \dot{\varphi}_{x}-\dot{z}_{2}, \\
& \dot{\Delta}_{3}=\dot{z}_{7}-\dot{z}_{3}=\dot{Z}+L_{2} \dot{\varphi}_{y}-L_{3} \dot{\varphi}_{x}-\dot{z}_{3} \\
& \dot{\Delta}_{4}=\dot{z}_{8}-\dot{z}_{4}=\dot{Z}+L_{2} \dot{\varphi}_{y}+L_{4} \dot{\varphi}_{x}-\dot{z}_{4} \\
& \dot{\Delta}_{u z 1}=\dot{z}_{13}-\dot{z}_{9}=\dot{z}_{13}-\dot{Z}-L_{9} \dot{\varphi}_{x}-L_{5}^{*} \dot{\varphi}_{y^{\prime}} \\
& \dot{\Delta}_{u z 2}=\dot{z}_{14}-\dot{z}_{10}=\dot{z}_{14}-\dot{Z}+L_{10} \dot{\varphi}_{x}-L_{6}^{*} \dot{\varphi}_{y^{\prime}} \\
& \dot{\Delta}_{u z 3}=\dot{z}_{15}-\dot{z}_{11}=\dot{z}_{15}-\dot{Z}+L_{11} \dot{\varphi}_{x}-L_{7} \dot{\varphi}_{y^{\prime}} \\
& \dot{\Delta}_{u z 4}=\dot{z}_{16}-\dot{z}_{12}=\dot{z}_{16}-\dot{Z}-L_{12} \dot{\varphi}_{x}-L_{8} \dot{\varphi}_{y^{\prime}} \\
& \dot{\Delta}_{w}=\dot{z}_{18}-\dot{z}_{17}=\dot{z}_{18}-\dot{Z}+L_{14} \dot{\varphi}_{x}-L_{13} \dot{\varphi}_{y^{\prime}}
\end{aligned}
$$

where $\dot{\Delta} \mathrm{ij}$ is the generalized velocity of deformation, $\ddot{\Delta} \mathrm{ij}$ is the generalized acceleration of deformation.

The nonlinear damping coefficients, $h_{s F 1}, h_{s F 2}, h_{s R 1}, h_{s R 2}$, in Equation (5), are functions of corresponding generalized coordinates. The final system of equations is:

$$
\begin{aligned}
& a_{i i} \dot{q}_{i}+b_{i 1} \dot{q}_{1}+b_{i 2} \dot{q}_{2}+\ldots+b_{i n} \dot{q}_{n}+c_{i 1} q_{1}+c_{i 2} q_{2}+\ldots+c_{i n} q_{n}= \\
& =d_{i 1} \eta_{1}+d_{i 2} \eta_{2}+d_{i 3} \eta_{3}+d_{i 4} \eta_{4}+d_{i 1}^{*} \dot{\eta}_{1}+d_{i 2}^{*} \dot{\eta}_{2}+d_{i 3}^{*} \dot{\eta}_{3}+d_{i 4}^{*} \dot{\eta}_{4}
\end{aligned}
$$

where $a, b, c, d, d^{*}$ (with corresponding indexes) are constants; $q_{i}$ is the generalized coordinates and $n$ is the number of generalized coordinates.

The coefficients $b_{i j}$, are the sums of coefficients for the linear and nonlinear parts of equations:

$$
b_{i j}=b_{i j(s)}+b_{i j(\text { nonl })}
$$

Equation (5) was solved in respect to the second derivative of the generalized coordinate, $\ddot{q}_{i}$. All nonlinear elements of the model were separated into nonlinear groups.

The solution of the equation was performed with Simulink software (Figure 3). 


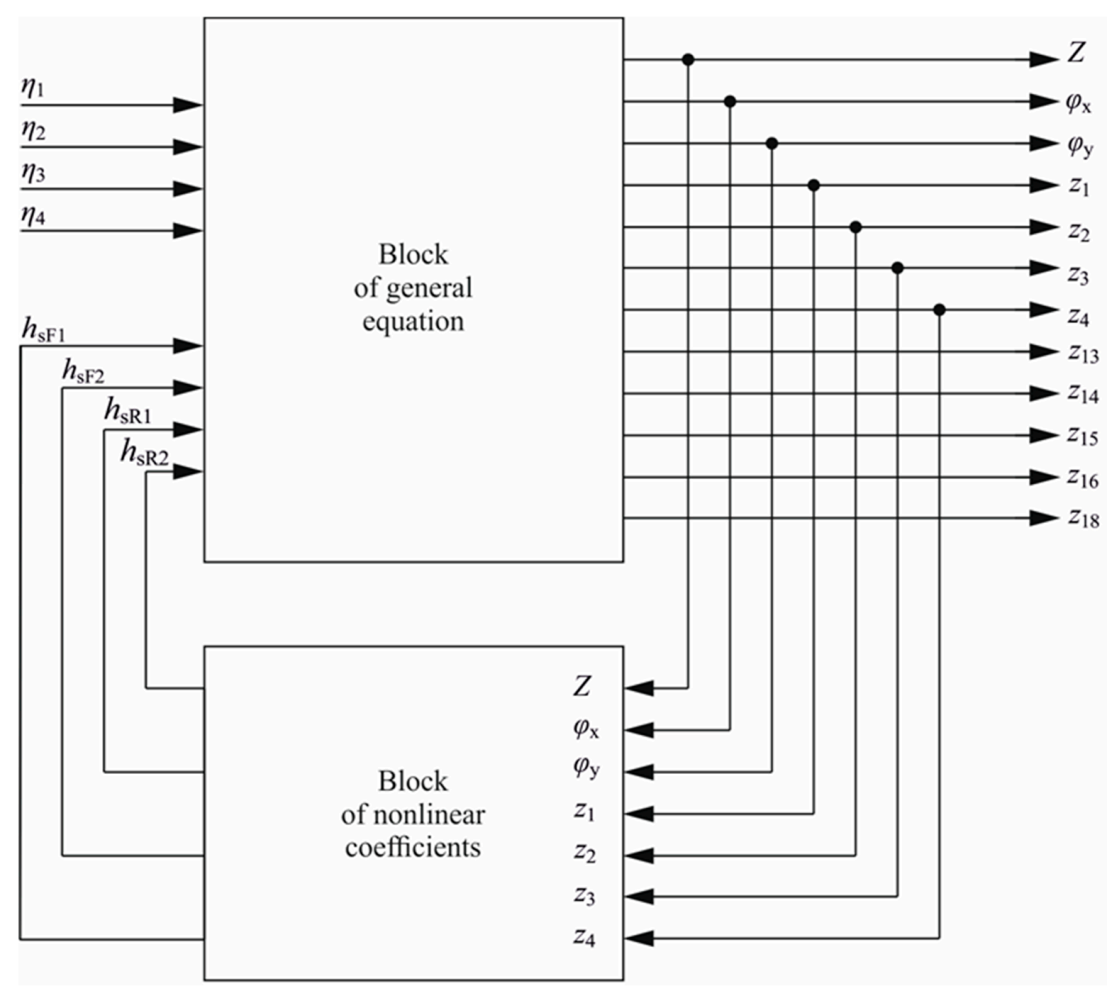

Figure 3. General structure of the dynamic model of the car.

The model consists of a linear part, presented by the block of general equations and a nonlinear part, represented by the block of nonlinear coefficients (Figure 3). The inputs to this model were the four coordinates from road roughness, acting in the model as kinematic excitation $\left(\eta_{1}, \eta_{2}, \eta_{3}\right.$ and $\left.\eta_{4}\right)$. The output of the model was the dynamic response of the system, as coordinates, $Z, \varphi_{x}, \varphi_{y}$ (coordinates of the plate, representing car body itself), $z_{1} \ldots z_{4}$ (coordinates of the wheel hub), $z_{13} \ldots z_{16}$ (coordinates of the center of masses of the driver and three passengers, respectively), $z_{18}$ (coordinate of center of mass of baggage in the baggage box). There were also some auxiliary coordinates, which were used to build the model. They had no influence on the dynamic behavior of the system.

\subsection{Damping Law Optimization}

The damping coefficient value is constant in common suspension vibration control systems. However, when kinematic excitation characteristics are changing, and the mass of the car (due to passengers or baggage) is changing, permanent damping becomes sub-optimal for all cases. To ensure the comfort of passengers for any case of mass presented in a car, the dependencies of damped and non-damped masses velocities on vibration velocity, should be known. From the theory of vibrations, it is known that the value of the damping coefficient, when the vibration energy is non-permanent, is a function of the vibration speed. The simplest and most logical function is polynomial, in which the damping coefficient depends on the vibration velocity and acceleration. As expected, such damping coefficients show much better results from the model, than permanent damping coefficients. Therefore, the damping coefficient was evaluated by second order polynomial. A higher-order polynomial was not applied, because the coefficient, $P_{3}$, appeared to be close to zero in the early modelling results. Therefore, the damping law was optimized, using a second order polynomial:

$$
h_{s F 1}=P_{0}+P_{1} \cdot a_{r e l}+P_{2} \cdot a_{r e l}^{2}
$$

where $a_{r e l}=\ddot{z}_{5}-\ddot{z}_{1}$. Damping coefficients, $h_{s F 2}, h_{s R 1}, h_{s R 2}$, were equal to $h_{s F 1}$. 
Parameter $P_{0}$ was changed a little, using data from the manufacturer (constant damping coefficient was $\left.h_{S F 1}=7500 \mathrm{Ns} / \mathrm{m}\right)$. Using this value, the resulting damping force $\left(F_{L F}\right)$ and the acceleration of the driver's body in the car $\left(Z_{13}\right)$ were calculated, and the optimal value of $P_{0}$ (when $F_{L F}$ is highest, and $Z_{13}$ is lowest) was observed. The coefficient, $P_{1}$, was found in the same way; however, in this case, the $P_{0}$ value was constant. The coefficient, $P_{2}$, was calculated with constant $P_{0}$ and $P_{1}$ values, which were determined as optimal.

\section{Results and Discussion}

\subsection{Experimental Results}

To generate the data for the model input, the experiments on roads of different roughness were performed (Figure 4). Road no. 6 showed displacement changes in the range of $\pm 50 \mathrm{~mm}$ and road no. 3 showed displacement changes in the range of $\pm 25 \mathrm{~mm}$.

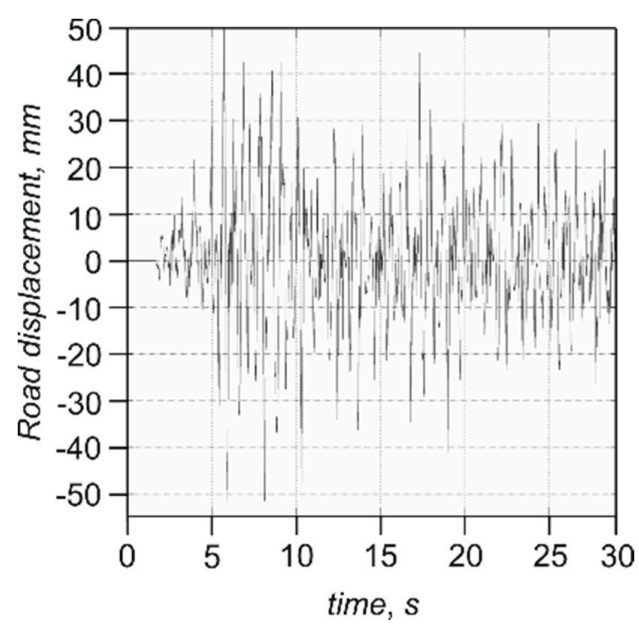

(a)

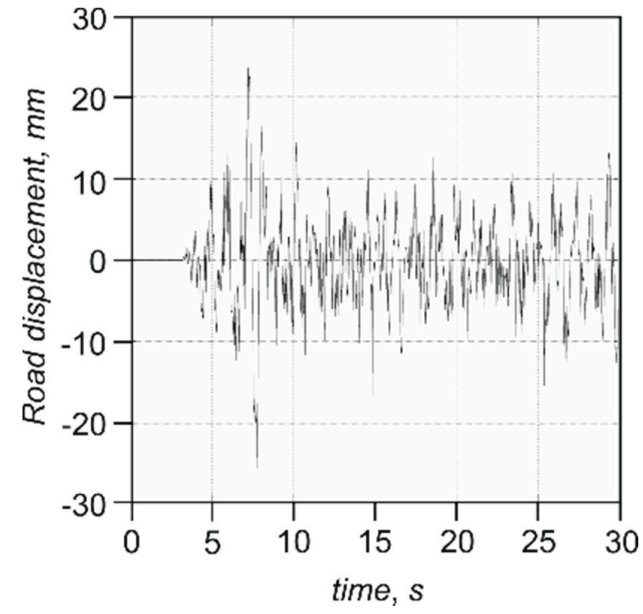

(b)

Figure 4. Road displacement dependencies on time, observed experimentally: (a) road no. 6; (b) road no. 3.

The experimental results (Figure 4) were compared with those of the theoretical model in Figure 5. The damping force from the measured suspension position, while driving at a speed of $60 \mathrm{kph}$ on road no. 3, was calculated by Equation (1). The value of the damping coefficient in the model was the same as used in the car $\left(h_{S F 1}=7500 \mathrm{Ns} / \mathrm{m}\right)$. It was found that root mean square (RMS) calculated from experimental data and the model, were in the same range-2000-2000 N.

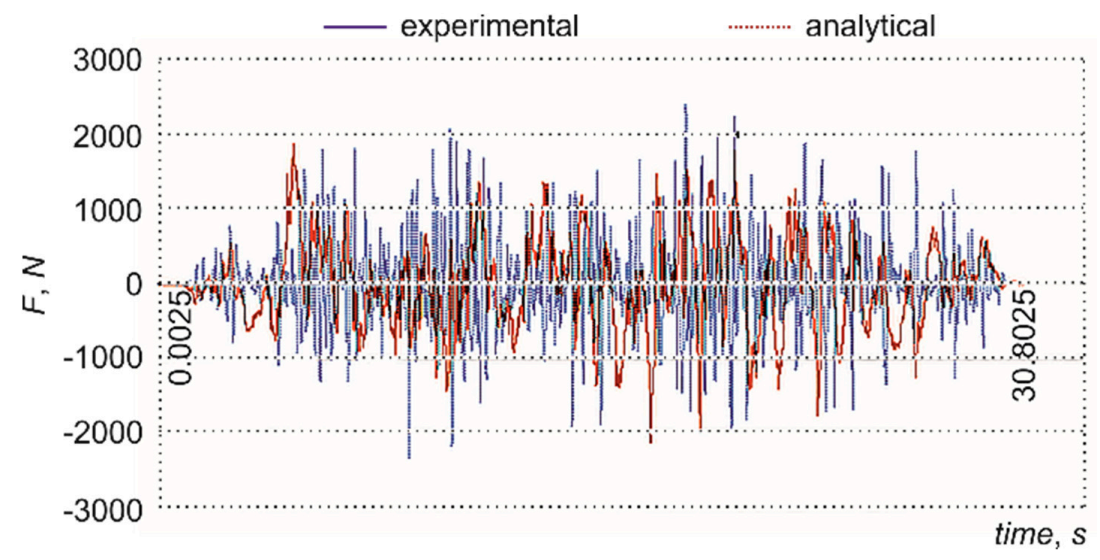

Figure 5. Experimental and analytical damping forces, F represents force. 


\subsection{Theoretical Results}

Numerical simulations were performed using the parameter values, revealed in Table 1 . In the simulation, passengers and baggage were eliminated, to get correct results that coincided with experimental research. Experiments were performed without passengers and baggage box masses, thus, the results from the model and experiments were comparable. It is possible to evaluate passengers and baggage box masses, if needed.

Table 1. Simulation parameters.

\begin{tabular}{|c|c|c|}
\hline Definition, Units & Value & Comments \\
\hline$h_{g}, \mathrm{Ns} / \mathrm{m}$ & 2064 & coefficient of damping of the load in the baggage box \\
\hline$h_{S F 1}, \mathrm{Ns} / \mathrm{m}$ & 7500 & constant or calculated by Equation (7). \\
\hline$h_{S F 2}, \mathrm{Ns} / \mathrm{m}$ & 7500 & constant or calculated by Equation (7). \\
\hline$h_{S R 1}, \mathrm{Ns} / \mathrm{m}$ & 7500 & constant or calculated by Equation (7). \\
\hline$h_{S R 2}, \mathrm{Ns} / \mathrm{m}$ & 7500 & constant or calculated by Equation (7). \\
\hline$h_{t F}, \mathrm{Ns} / \mathrm{m}$ & 300 & coefficient of damping of front tire \\
\hline$h_{t R}, \mathrm{Ns} / \mathrm{m}$ & 300 & coefficient of damping of rear tire \\
\hline$h_{u z 1}, \mathrm{Ns} / \mathrm{m}$ & 2064 & coefficient of damping of human body (driver) \\
\hline$h_{u z 2}, \mathrm{Ns} / \mathrm{m}$ & 2064 & coefficient of damping of front right passenger \\
\hline$h_{u z 3}, \mathrm{Ns} / \mathrm{m}$ & 2064 & coefficient of damping of rear right passenger \\
\hline$h_{u z 4}, \mathrm{Ns} / \mathrm{m}$ & 2064 & coefficient of damping of rear left passenger \\
\hline$J_{x}, \mathrm{~kg} \cdot \mathrm{m}^{2}$ & 670 & moment of inertia of the vehicle around $X$ axis \\
\hline$J_{x y}, \mathrm{~kg} \cdot \mathrm{m}^{2}$ & 0 & mixed moment of inertia \\
\hline$J_{y}, \mathrm{~kg} \cdot \mathrm{m}^{2}$ & 2900 & moment of inertia of the vehicle around $Y$ axis \\
\hline$k_{g}, \mathrm{~N} / \mathrm{m}$ & 90,000 & coefficient of stiffness of the load in baggage box \\
\hline$k_{s F}, \mathrm{~N} / \mathrm{m}$ & 49,976 & stiffness of front wheel suspension (single side) \\
\hline$k_{s R}, \mathrm{~N} / \mathrm{m}$ & $87,898.5$ & stiffness of rear wheel suspension (single side) \\
\hline$k_{t F}, \mathrm{~N} / \mathrm{m}$ & 270,000 & stiffness of front tire \\
\hline$k_{t R}, \mathrm{~N} / \mathrm{m}$ & 270,000 & stiffness of rear tire \\
\hline$k_{u z 1}, \mathrm{~N} / \mathrm{m}$ & 90,000 & coefficient of stiffness of driver body \\
\hline$k_{u z 2}, \mathrm{~N} / \mathrm{m}$ & 90,000 & coefficient of stiffness of front right passenger body \\
\hline$k_{u z 3}, \mathrm{~N} / \mathrm{m}$ & 90,000 & coefficient of stiffness of rear right passenger body \\
\hline$k_{u z 4}, \mathrm{~N} / \mathrm{m}$ & 90,000 & coefficient of stiffness of rear left passenger body \\
\hline$L_{1}, \mathrm{~m}$ & 1.7867 & distance, represented in dynamical model \\
\hline$L_{10}, \mathrm{~m}$ & 0.422625 & distance, represented in dynamical model \\
\hline$L_{11}, \mathrm{~m}$ & 0.422625 & distance, represented in dynamical model \\
\hline$L_{12}, \mathrm{~m}$ & 0.422625 & distance, represented in dynamical model \\
\hline$L_{13}, \mathrm{~m}$ & 1.4286 & distance, represented in dynamical model \\
\hline$L_{14}, \mathrm{~m}$ & 0.1 & distance, represented in dynamical model \\
\hline$L_{2}, \mathrm{~m}$ & 1.1363 & distance, represented in dynamical model \\
\hline$L_{3}, \mathrm{~m}$ & 0.84525 & distance, represented in dynamical model \\
\hline$L_{4}, \mathrm{~m}$ & 0.84525 & distance, represented in dynamical model \\
\hline$L_{5}, \mathrm{~m}$ & 0.47135 & distance, represented in dynamical model \\
\hline$L_{6}, \mathrm{~m}$ & 0.47135 & distance, represented in dynamical model \\
\hline$L_{7}, \mathrm{~m}$ & 0.99015 & distance, represented in dynamical model \\
\hline$L_{8}, \mathrm{~m}$ & 0.99015 & distance, represented in dynamical model \\
\hline$L_{9}, \mathrm{~m}$ & 0.422625 & distance, represented in dynamical model \\
\hline$M, \mathrm{~kg}$ & 2613 & mass of the vehicle \\
\hline$m_{1}, \mathrm{~kg}$ & 80 & mass of driver \\
\hline$m_{2}, \mathrm{~kg}$ & 0.01 & front right passenger mass \\
\hline$m_{3}, \mathrm{~kg}$ & 0.01 & rear right passenger mass \\
\hline$m_{4}, \mathrm{~kg}$ & 0.01 & rear left passenger mass \\
\hline$m_{w}, \mathrm{~kg}$ & 0.01 & mass of the load in baggage box \\
\hline$m_{w f}, \mathrm{~kg}$ & 94 & mass of the front wheel with belonging parts \\
\hline$m_{w r}, \mathrm{~kg}$ & 80.9 & mass of the rear wheel with belonging parts \\
\hline$x_{c}, \mathrm{~m}$ & 0.3617 & coordinate of center of gravity on $X$ axis \\
\hline$y_{c}, \mathrm{~m}$ & 0 & coordinate of center of gravity on $Y$ axis \\
\hline
\end{tabular}


Experimentally observed road profiles were used as model inputs (Figure 5). Results of the analysis were evaluated by two parameters: signal extremities and RMS over time. The peaks are important for evaluating the maximum possible impacts to the vehicle suspension system. The level of vibration or dominating force were evaluated by RMS values. The damping power for each road was calculated with both constant damping coefficients $\left(h_{S F 1}=7500 \mathrm{Ns} / \mathrm{m}\right)$ and optimized by Equation (7). The calculated damping power for road no. 6 is shown in Figure 6. The optimized damping law gave the possibility of harvesting more power from vibration-the power RMS with optimized damping law was $407.5 \mathrm{~W}$, while permanent damping gave $301.3 \mathrm{~W}$ of power. When the roughness was lower (road no. 3), the optimized damping law had a lesser influence on damping power (Figure 7): permanent damping gave $218.7 \mathrm{~W}$, while optimized damping law gave $284.4 \mathrm{~W}$. The higher damping power meant that more energy could be harvested from the shock absorber, therefore, from comparing the results of common and optimized damping controls, we can conclude that our method is effective even on roads with low levels of roughness. In the literature, smaller damping power values have been provided: $19 \mathrm{~W}$ [42], $33 \mathrm{~W}$ [43] and 40.4 W [44]. Cassidy et al proposed an electromechanical transducer, which generated over $100 \mathrm{~W}$ of power [45]. Our device simulated power was higher by several fold (from 15 (at $19 \mathrm{~W}$ ) to 2.84-fold (at $100 \mathrm{~W})$ ). However, comparing the damping power observed using different devices is not appropriate; authors designed their own damper-harvester systems with different control conceptions and different designs. Experiments were performed on different road roughness and at different speeds. Therefore, we can only compare results which show improvement using the same device control as in the current study - we observed $26 \%$ more power on roads with high roughness, and $23 \%$ more power on medium roughness roads, when the optimized control law was applied.

The coefficients of damping dependencies, over time, for roads of different roughness, with optimized damping laws, are shown in Figure 8. The damping system adapts to the road roughness and creates more comfort for passengers. At the same time, the energy dissipated in the damper, could be more accurately harvested than in classical energy harvesters. Compared to research by Tang et al., where the damping coefficient was observed as 1680-2142 Ns/m [43], which is in good agreement with our research.

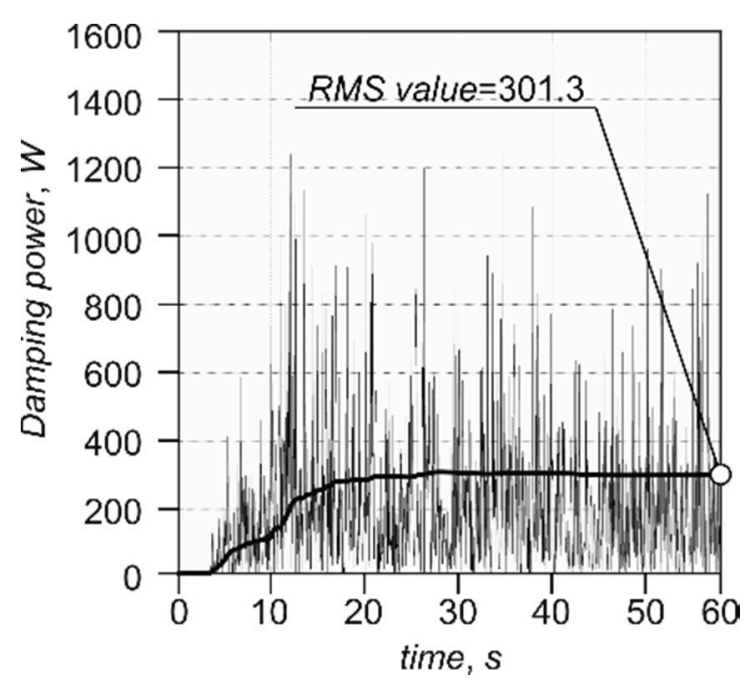

(a)

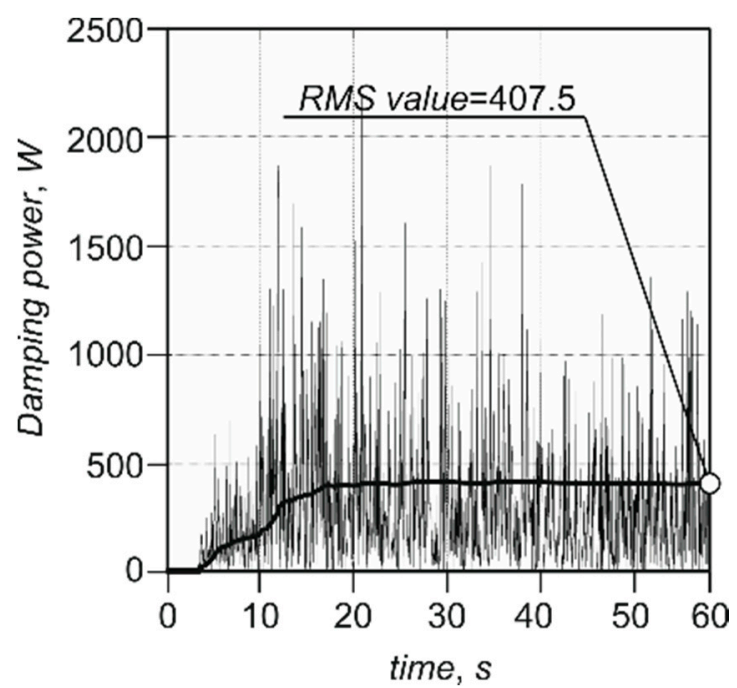

(b)

Figure 6. Damping power dependencies over time, obtained from the model for road no. 6: (a) Permanent damping with $h_{S F 1}=7500 \mathrm{Ns} / \mathrm{m}$; (b) Optimized damping law. RMS—root mean square. 


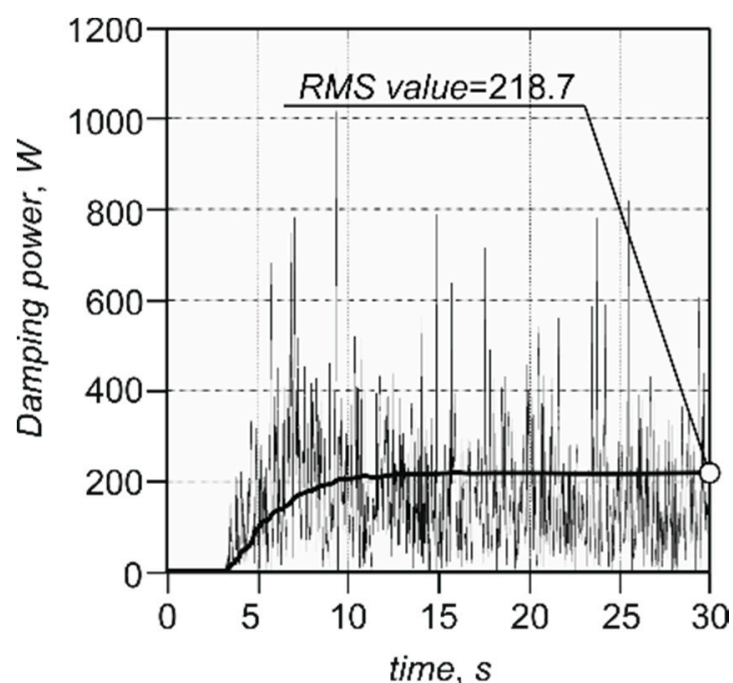

(a)

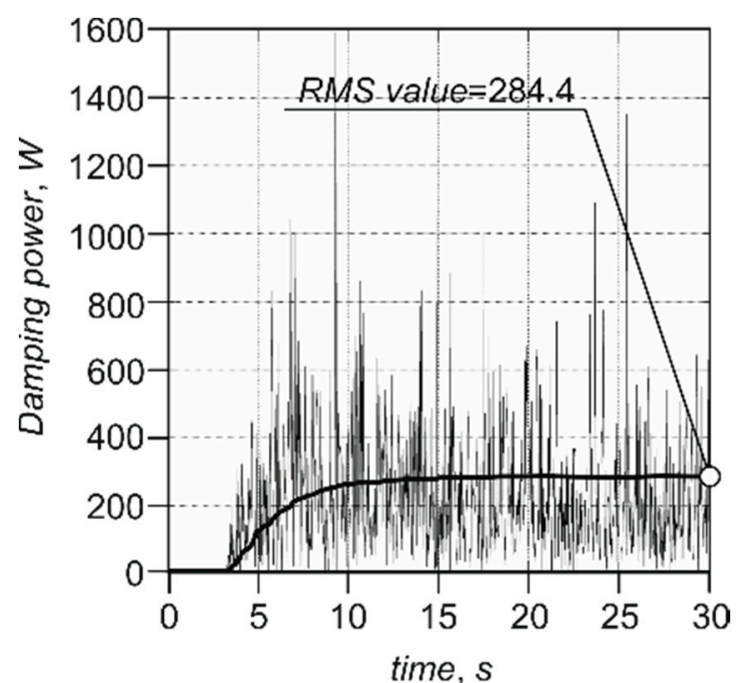

(b)

Figure 7. Damping power dependencies on time, obtained from the model for road no. 3: (a) Permanent damping with $h_{S F 1}=7500 \mathrm{Ns} / \mathrm{m}$; (b) Optimized damping law.

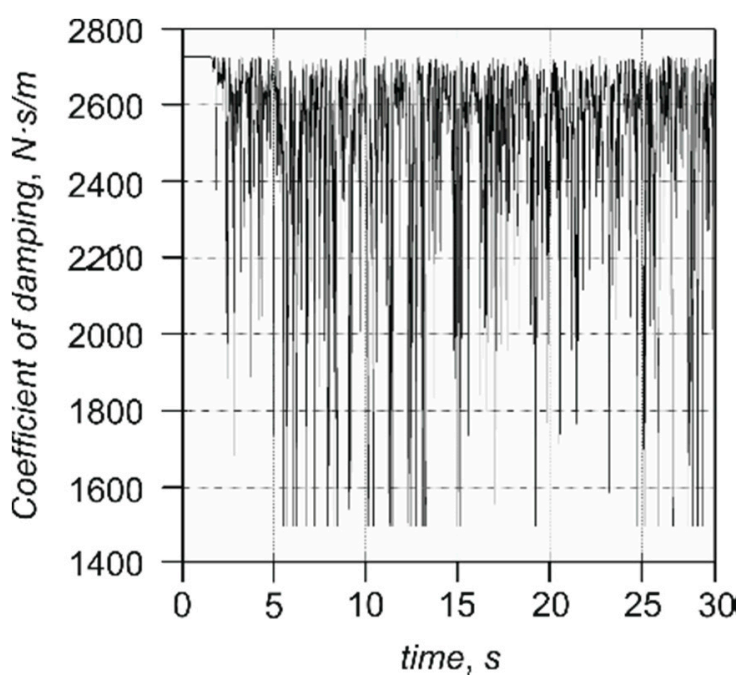

(a)

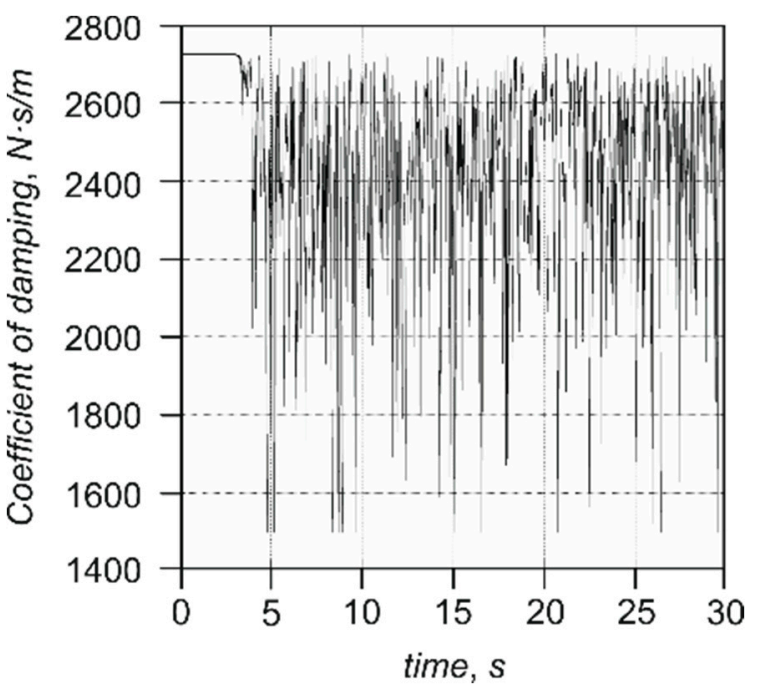

(b)

Figure 8. Coefficients of damping $\left(h_{S F 1}\right)$ with optimized damping law dependencies, over time: (a) for road no. $6, P_{0}=5765, P_{1}=-19, P_{2}=0.5 ;(\mathbf{b})$ for road no. $3 ; P_{0}=5050, P_{1}=30, P_{2}=0.45$.

The damping force was calculated for each road with different roughness and different damping laws. It was found that for road no. 6, with permanent damping, the force RMS value was $301.5 \mathrm{~N}$, while the optimized law RMS value was $410 \mathrm{~N}$ (Figure 9). For road no. 3, permanent damping gave a force of $218.9 \mathrm{~N}$, while optimized damping gave $284.05 \mathrm{~N}$ (Figure 10). The results were similar to the harvested power: the optimized damping law had more influence on road no. 6, which was coarser than road no. 3. Chen et al. observed damping forces in the range of -600 to $600 \mathrm{~N}$ [46], while Cassidy et al. observed quite a high maximal force of $1 \mathrm{kN}$ [45]. Our forces were calculated in RMS; therefore, they were a little bit lower compared to those measured by other authors. However, our maximal forces were in agreement with other research. 


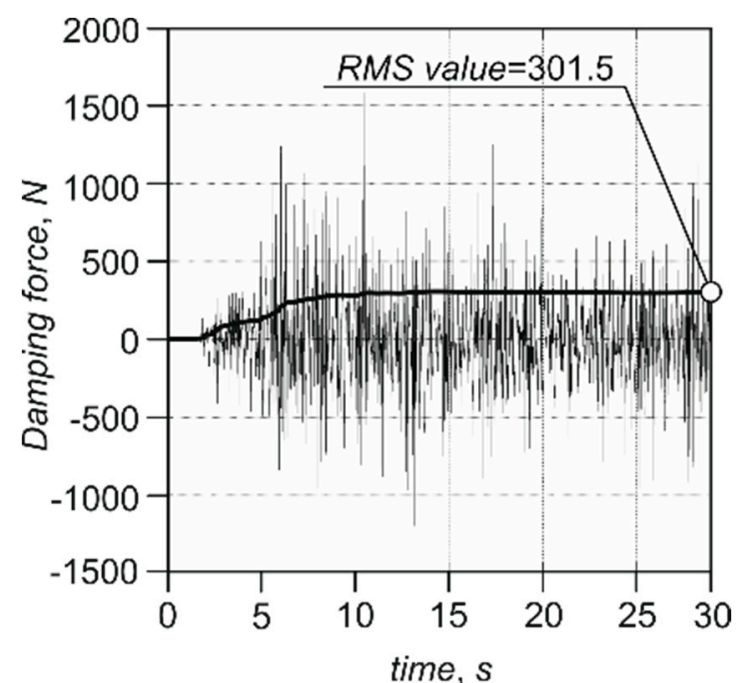

(a)

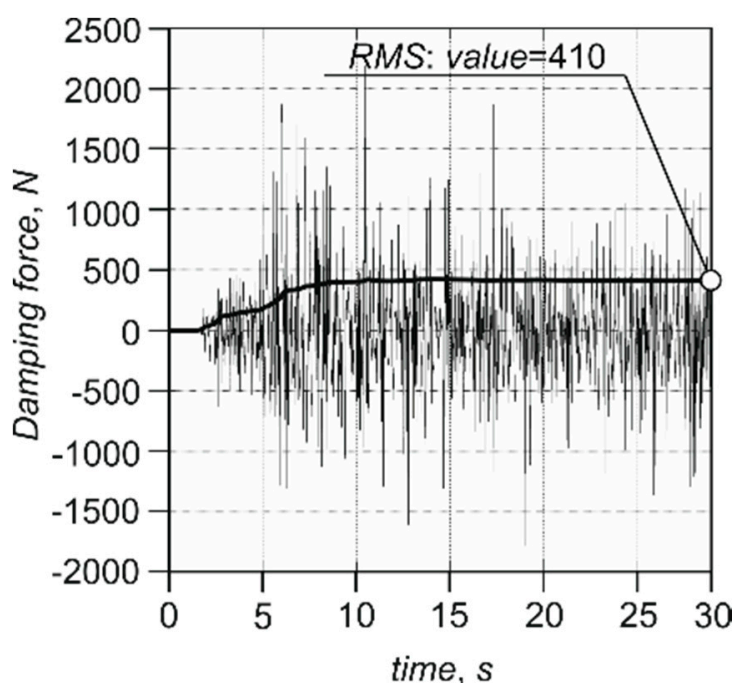

(b)

Figure 9. Damping force dependencies, over time, for road no. 6: (a) with permanent damping $\left(h_{S F 1}=7500 \mathrm{Ns} / \mathrm{m}\right) ;(\mathbf{b})$ with the optimized damping law.

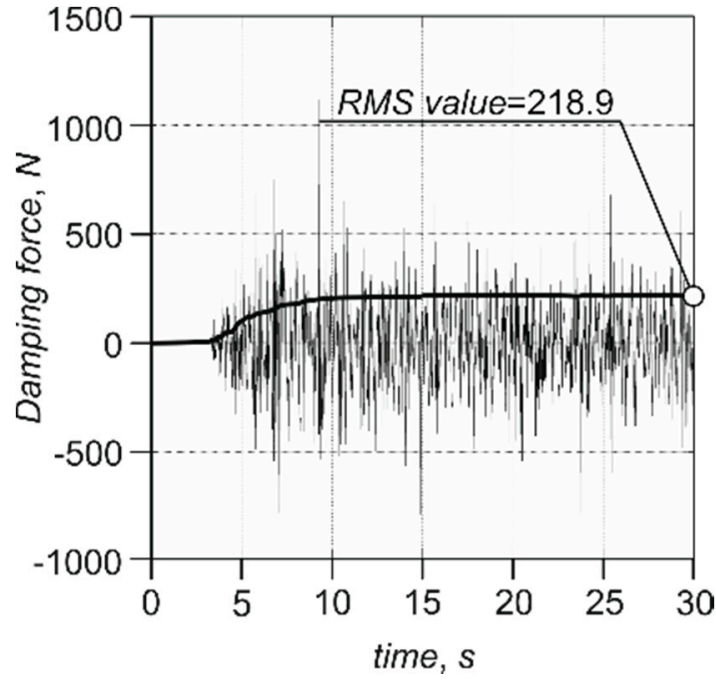

(a)

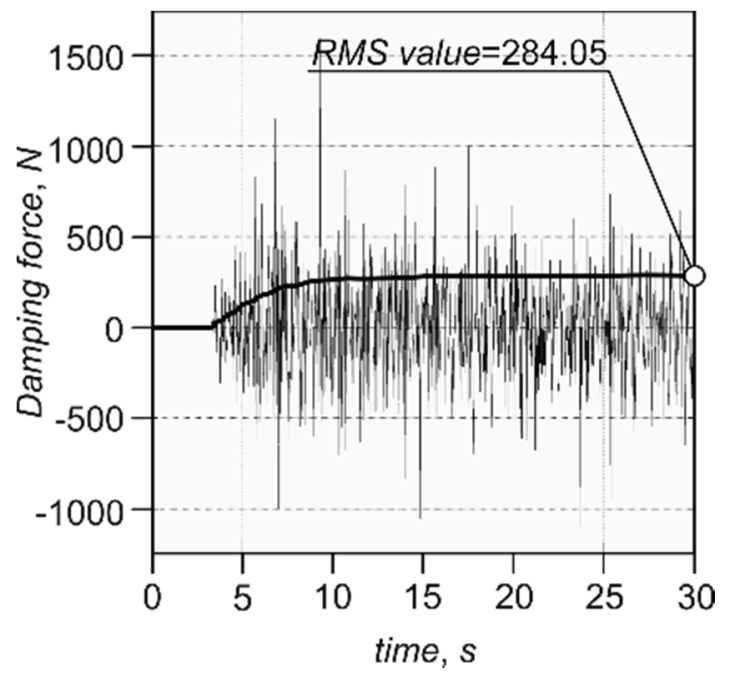

(b)

Figure 10. Damping force dependencies, over time, for road no. 3: (a) with permanent damping $\left(h_{S F 1}=7500 \mathrm{Ns} / \mathrm{m}\right) ;(\mathbf{b})$ with the optimized damping law.

\section{Conclusions}

Limitations in the common damping control system with constant damping coefficients, motivated us to propose a new method to control automobile suspension vibrations. The polynomial damping law allowed us to find the optimal damping coefficient, whose application to a suspension system resulted in diminished accelerations of the car body and an increased level of comfort for passengers. Also, the application of polynomial damping can increase a lifetime of the car and decrease the development of various defects in the car body and equipment. RMS values for accelerations on road no. 3 decreased by up to $20 \%$, in comparison with classical shock absorbers. Controlled damping increased dissipated power of damped vibrations in a similar range. At a speed of $60 \mathrm{kph}$, the Range Rover Evoque could reach $400 \mathrm{~W}$ RMS for one shock absorber. This case was characterized by a very rough road; nevertheless, $200 \mathrm{~W}$ in vibrations is achievable for the majority of test cases. An increase in damping efficiency will significantly increase the load on suspension elements and consequently the damping 
power. Damping power can be a good diagnostic feature for damping efficiency. Different behaviors of shock absorbers, placed in the same car, can specify problems in the suspension. The damping coefficient change is assumed to be self-adjusted, so a rapid change in road conditions, such as an accidental bump, will be better treated. Our device simulated power was higher by several fold (from 15 (at $19 \mathrm{~W}$ ) to 2.84 times (at $100 \mathrm{~W})$ ). Maximal forces were in agreement with another author's research.

The estimated need for power is $12 \mathrm{~W}$, which includes control of the shock absorber itself and the powering of data processing, and data transmitting units, which are usually used in automobiles. Therefore, our control method can be applied to harvest more energy than in common shock absorbers, and to power electronic devices.

Acknowledgments: The research was supported by ECSEL Joint Undertaking under the project nr 662192 3Ccar: Integrated Components for Complexity Control in affordable electrified cars.

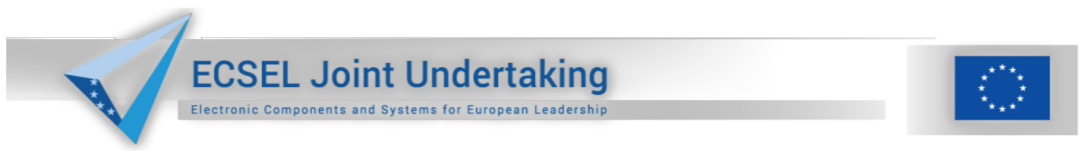

Author Contributions: All authors have prepared, analyzed and approved the final manuscript.

Conflicts of Interest: The authors declare no conflict of interest.

\section{References}

1. Cassidy, I.L.; Scruggs, J.T.; Behrens, S.; Gavin, H.P. Design and experimental characterization of an electromagnetic transducer for large-scale vibratory energy harvesting applications. J. Intell. Mater. Syst. Struct. 2011, 22, 2009-2024. [CrossRef]

2. Zhu, S.; Shen, W.-A.; $\mathrm{Xu}, \mathrm{Y}$.-L. Linear electromagnetic devices for vibration damping and energy harvesting: Modeling and testing. Eng. Struct. 2012, 34, 198-212. [CrossRef]

3. Tang, X.; Zuo, L. Simultaneous energy harvesting and vibration control of structures with tuned mass dampers. J. Intell. Mater. Syst. Struct. 2012, 23, 2117-2127. [CrossRef]

4. Ali, S.F.; Adhikari, S. Energy harvesting dynamic vibration absorbers. J. Appl. Mech. 2013, 80, 41004. [CrossRef]

5. Gonzalez-Buelga, A.; Clare, L.; Cammarano, A.; Neild, S.; Burrow, S.; Inman, D. An optimised tuned mass damper/harvester device. Struct. Control Health Monit. 2014, 21, 1154-1169. [CrossRef]

6. Zhu, J.; Zhang, W. Coupled analysis of multi-impact energy harvesting from low-frequency wind induced vibrations. Smart Mater. Struct. 2015, 24, 45007. [CrossRef]

7. Madhav, C.; Ali, S.F. Harvesting Energy from Vibration Absorber under Random Excitations. IFAC-Pap. 2016, 49, 807-812. [CrossRef]

8. Salvi, J.; Giaralis, A. Concept Study of A Novel Energy Harvesting-Enabled Tuned Mass-Damper-Inerter (EH-TMDI) Device for Vibration Control of Harmonically-Excited Structures. J. Phys. Conf. Ser. 2016, 744, 012082. [CrossRef]

9. Luo, Y.; Sun, H.; Wang, X.; Zuo, L.; Chen, N. Wind Induced Vibration Control and Energy Harvesting of Electromagnetic Resonant Shunt Tuned Mass-Damper-Inerter for Building Structures. Shock Vib. 2017, 2017, 1-13. [CrossRef]

10. Takeya, K.; Sasaki, E.; Kobayashi, Y. Design and parametric study on energy harvesting from bridge vibration using tuned dual-mass damper systems. J. Sound Vib. 2016, 361, 50-65. [CrossRef]

11. Awrejcewicz, J.; Olejnik, P. Active control of two degrees-of-freedom building-ground system. Arch. Control Sci. 2007, 17, 393-408.

12. Liao, Y.; Sodano, H.A. Model of a single mode energy harvester and properties for optimal power generation. Smart Mater. Struct. 2008, 17, 65026. [CrossRef]

13. Simon, P.; Yves, S.-A. Improving the performance of a piezoelectric energy harvester using a variable thickness beam. Smart Mater. Struct. 2010, 19, 105020.

14. Bucinskas, V. Energy Harvesting Shock Absorber and Method for Controlling Same. U.S. Patent 20140027217 A1, 30 January 2014. 
15. Bucinskas, V.; Klevinskis, A.; Sesok, N.; Iljin, I.; Warsza, Z.L. Evaluation of damping characteristics of a damper with magneto-rheological fluid. In Advanced Mechatronics Solutions; Jablonski, R., Brezina, T., Eds.; Springer: Cham, Switzerland, 2016; pp. 411-420.

16. Mitrouchev, P.; Klevinskis, A.; Bucinskas, V.; Dragasius, E.; Udris, D.; Morkvenaite-Vilkonciene, I. Analytical research of damping efficiency and heat generation of magnetorheological damper. Smart Mater. Struct. 2017, 26, 65026. [CrossRef]

17. Lei, Z.; Brian, S.; Jurgen, S.; Yu, Z. Design and characterization of an electromagnetic energy harvester for vehicle suspensions. Smart Mater. Struct. 2010, 19, 45003.

18. Abed, I.; Kacem, N.; Bouhaddi, N.; Bouazizi, M.L. Multi-modal vibration energy harvesting approach based on nonlinear oscillator arrays under magnetic levitation. Smart Mater. Struct. 2016, 25, 25018. [CrossRef]

19. Kacem, N.; Baguet, S.; Hentz, S.; Dufour, R. Nonlinear phenomena in nanomechanical resonators: Mechanical behaviors and physical limitations. Mech. Ind. 2010, 11, 521-529. [CrossRef]

20. Czop, P.; Sławik, D. A high-frequency first-principle model of a shock absorber and servo-hydraulic tester. Mech. Syst. Signal Process. 2011, 25, 1937-1955. [CrossRef]

21. Lam, A.H.-F.; Liao, W.-H. Semi-active control of automotive suspension systems with magneto-rheological dampers. Int. J. Veh. Des. 2003, 33, 50-75. [CrossRef]

22. Lee, H.-S.; Choi, S.-B. Control and response characteristics of a magneto-rheological fluid damper for passenger vehicles. J. Intell. Mater. Syst. Struct. 2000, 11, 80-87. [CrossRef]

23. Li, S.; Lu, Y.; Li, L. Dynamical test and modeling for hydraulic shock absorber on heavy vehicle under harmonic and random loadings. Res. J. Appl. Sci. Eng. Technol. 2012, 4, 1903-1910.

24. Worden, K.; Hickey, D.; Haroon, M.; Adams, D.E. Nonlinear system identification of automotive dampers: A time and frequency-domain analysis. Mech. Syst. Signal Process. 2009, 23, 104-126. [CrossRef]

25. Zubieta, M.; Elejabarrieta, M.J.; Bou-Ali, M.M. Characterization and modeling of the static and dynamic friction in a damper. Mech. Mach. Theory 2009, 44, 1560-1569. [CrossRef]

26. Lajqi, S.; Pehan, S. Designs and optimizations of active and semi-active non-linear suspension systems for a terrain vehicle. Stroj. Vestnik J. Mech. Eng. 2012, 58, 732-743. [CrossRef]

27. Mangal, S.K.; Kumar, A. Geometric parameter optimization of magneto-rheological damper using design of experiment technique. Int. J. Mech. Mater. Eng. 2015, 10, 4. [CrossRef]

28. Hudha, K.; Jamaluddin, H.; Samin, P.M.; Rahman, R.A. Non-parametric linearised data driven modelling and force tracking control of a magnetorheological damper. Int. J. Veh. Des. 2008, 46, 250-269. [CrossRef]

29. Muhammad, A.; Yao, X.-L.; Deng, Z.-C. Review of magnetorheological (MR) fluids and its applications in vibration control. J. Mar. Sci. Appl. 2006, 5, 17-29. [CrossRef]

30. Sapiński, B.; Rosół, M.; Węgrzynowski, M. Investigation of an energy harvesting MR damper in a vibration control system. Smart Mater. Struct. 2016, 25, 125017. [CrossRef]

31. Jastrzębski, Ł.; Sapiński, B. Electrical interface for an MR damper-based vibration reduction system with energy harvesting capability. In Proceedings of the IEEE 18th International Carpathian Control Conference (ICCC), Sinaia, Romania, 28-31 May 2017; pp. 189-192.

32. Hu, G.; Tang, L.; Banerjee, A.; Das, R. Metastructure With Piezoelectric Element for Simultaneous Vibration Suppression and Energy Harvesting. J. Vib. Acoust. 2017, 139, 11012. [CrossRef]

33. Hu, G.; Tang, L.; Das, R. Metamaterial-inspired piezoelectric system with dual functionalities: Energy harvesting and vibration suppression, Active and Passive Smart Structures and Integrated Systems. In Proceedings of the International Society for Optics and Photonics, Portland, OR, USA, 11-16 April 2017; p. 101641X.

34. Bowden, J.A.; Burrow, S.G.; Cammarano, A.; Clare, L.R.; Mitcheson, P.D. Switched-mode load impedance synthesis to parametrically tune electromagnetic vibration energy harvesters. IEEE/ASME Trans. Mechatron. 2015, 20, 603-610. [CrossRef]

35. Mitcheson, P.D.; Toh, T.T.; Wong, K.H.; Burrow, S.G.; Holmes, A.S. Tuning the resonant frequency and damping of an electromagnetic energy harvester using power electronics. IEEE Trans. Circuits Syst. II 2011, 58, 792-796. [CrossRef]

36. Balato, M.; Costanzo, L.; Vitelli, M. Resonant electromagnetic vibration harvesters: Determination of the equivalent electric circuit parameters and simplified closed-form analysis for the identification of the optimal diode bridge rectifier DC load. Int. J. Electr. Power Energy Syst. 2017, 84, 111-123. [CrossRef] 
37. Balato, M.; Costanzo, L.; Vitelli, M. Maximization of the extracted power in resonant electromagnetic vibration harvesters applications employing bridge rectifiers. Sens. Actuators A 2017, 263, 63-75. [CrossRef]

38. Bakar, S.A.A.; Jamaluddin, H.; Rahman, R.A.; Samin, P.M.; Masuda, R.; Hashimoto, H.; Inaba, T. Modelling of magnetorheological semi-active suspension system controlled by semi-active damping force estimator. Int. J. Comput. Appl. Technol. 2011, 42, 49-64. [CrossRef]

39. Goncalves, F.D.; Ahmadian, M. A hybrid control policy for semi-active vehicle suspensions. Shock Vib. 2003, 10,59-69. [CrossRef]

40. Ahmadian, M.; Vahdati, N. Transient dynamics of semiactive suspensions with hybrid control. J. Intell. Mater. Syst. Struct. 2006, 17, 145-153. [CrossRef]

41. Wang, W.L.; Yang, X.J.; Xu, G.X.; Huang, Y. Multi-objective design optimization of the complete valve system in an adjustable linear hydraulic damper. Proc. Inst. Mech. Eng. Part C J. Mech. Eng. Sci. 2011, 225, 679-699. [CrossRef]

42. Li, Z.; Zuo, L.; Luhrs, G.; Lin, L.; Qin, Y.-X. Electromagnetic energy-harvesting shock absorbers: Design, modeling, and road tests. IEEE Trans. Veh. Technol. 2013, 62, 1065-1074. [CrossRef]

43. Tang, X.; Lin, T.; Zuo, L. Design and optimization of a tubular linear electromagnetic vibration energy harvester. IEEE/ASME Trans. Mechatron. 2014, 19, 615-622. [CrossRef]

44. Li, Z.; Zuo, L.; Kuang, J.; Luhrs, G. Energy-harvesting shock absorber with a mechanical motion rectifier. Smart Mater. Struct. 2012, 22, 25008. [CrossRef]

45. Cassidy, I.L.; Scruggs, J.T.; Behrens, S. Design of electromagnetic energy harvesters for large-scale structural vibration applications. In Proceedings of the Society of Photo-Optical Instrumentation Engineers 7977, Active and Passive Smart Structures and Integrated Systems, San Diego, CA, USA, 27 April 2011; p. 79770P.

46. Chen, C.; Liao, W.-H. A self-sensing magnetorheological damper with power generation. Smart Mater. Struct. 2012, 21, 25014. [CrossRef]

(C) 2017 by the authors. Licensee MDPI, Basel, Switzerland. This article is an open access article distributed under the terms and conditions of the Creative Commons Attribution (CC BY) license (http:/ / creativecommons.org/licenses/by/4.0/). 